\title{
Genetic regulation of aflatoxin, ochratoxin $A$, trichothecene, and fumonisin biosynthesis: A review
}

\author{
Jéssica Gil-Serna ${ }^{1} \cdot$ Covadonga Vázquez $^{1} \cdot$ Belén Patiño $^{1}$ \\ Received: 11 March 2019 / Revised: 8 May 2019 / Accepted: 13 May 2019 / Published online: 29 May 2019 \\ (C) Springer Nature Switzerland AG 2019
}

\begin{abstract}
Mycotoxins are a significant food safety concern. Aflatoxins, trichothecenes, fumonisins, and ochratoxin A are considered the most important mycotoxins due to their frequent occurrence in food products and their well-known toxicity. The regulation of mycotoxin biosynthesis occurs mainly at transcriptional level, and specific regulators have been described in every biosynthetic cluster. Secondary metabolite production, including mycotoxin synthesis, is also regulated by general regulator pathways affected by light, osmotic stress and oxidative stress, among others. This review is focused on this genetic regulation of mycotoxin biosynthesis by specific genes and global regulators.
\end{abstract}

Keywords Aflatoxins $\cdot$ Trichothecenes $\cdot$ Fumonisin $\cdot$ Ochratoxin A $\cdot$ Biosynthetic cluster $\cdot$ Transcription factors

\section{Introduction}

Mycotoxins are fungal secondary metabolites that often contaminate foodstuffs and beverages, dramatically threatening food safety. These compounds are toxic for animals and humans and some of them are even considered as carcinogens. Maximum levels of certain mycotoxins in food products are strongly regulated in different countries including the European Union (CE 1881/2006).

The biosynthetic genes involved in secondary metabolite production are often clustered in fungi, which facilitates coordination of their transcriptional activation and regulation (Shwab and Keller 2008). Many studies have been focused on elucidating the genetic basis of mycotoxin biosynthesis, and the complete gene clusters involved in the biosynthesis of most of mycotoxins are now known. Each cluster presents at least one specific regulatory gene encoding a protein that binds to the promoter of biosynthetic genes and assists in recruiting RNA polymerase II to initiate transcription (Woloshuk and Shim 2013). However, other general regulator pathways seem to be able to affect mycotoxin production

Jéssica Gil-Serna

jgilsern@ucm.es

1 Department of Genetics, Physiology and Microbiology, Faculty of Biology, Complutense University of Madrid, Jose Antonio Nováis 12, 28040 Madrid, Spain
(Wang et al. 2016). This review is focused on the transcriptional regulation of the biosynthesis of the main mycotoxins regarding their frequent occurrence in food products and their well-known toxicity towards both animals and humans: aflatoxins, trichothecenes, fumonisins, and ochratoxin A.

\section{Genetic basis of mycotoxin biosynthesis and regulation by specific regulatory genes}

\section{Aflatoxins}

Aflatoxins are currently considered the most important mycotoxins due to their common occurrence in foodstuffs and their highly toxic properties (Kumar et al. 2017). There are many types of aflatoxins although the most well-known and naturally occurring are $B_{1}, B_{2}, G_{1}$, and $G_{2}$ (Lizarraga-Paulín et al. 2011). The International Agency for Research on Cancer has classified aflatoxin $\mathrm{B}_{1}\left(\mathrm{AFB}_{1}\right)$ as a group 1 carcinogen, and it is considered the most potent naturally occurring carcinogen (Gil-Serna et al. 2014). The dietary exposure to $\mathrm{AFB}_{1}$ leads to chronic liver damage, growth suppression, malnutrition, and affects immune function (Rushing and Selim 2019) The main aflatoxin producers are Aspergillus flavus, A. parasiticus, and A. nomius that usually infect cereals, oilseeds, spices and nuts (Kumar et al. 2017).

The cluster of genes involved in aflatoxin biosynthesis has been extensively studied both in A. flavus and A. parasiticus. 
The first cloned and described gene involved in aflatoxin biosynthesis encodes an O-methyltransferase and was called nor 1 (Yu et al. 1993). Up to now, all the genes involved in the biosynthetic pathway are known to be clustered within a 75$\mathrm{kb}$ region on chromosome III, $80 \mathrm{~kb}$ from the telomere ( $\mathrm{Yu}$ 2012). This genomic region contains 27 genes that encode different enzymes directly involved in some steps of the biosynthetic pathway, as well as two regulatory genes. The scheme of the relative position of the genes in the cluster is shown in Fig. 1. These genes were traditionally named after the substrate they converted or their enzymatic functions, which reveals to be very complex and ambiguous. Therefore, Yu et al. (2004) proposed a consensus for gene naming in the case of aflatoxin biosynthetic genes that used the letter code afl followed by a letter in alphabetical order, which represents the gene.

The aflR gene encodes a zinc-finger transcription factor that is required for the activation of other clustered genes and is considered to be specifically involved in the regulation of aflatoxin biosynthesis (Yu and Ehrlich 2011). This transcription factor binds to the palindromic site $5^{\prime}-\mathrm{TCGN}_{5} \mathrm{CGA}-3^{\prime}$, which has been found within the promoter of all structural genes (Cary and Calvo 2008). The gene aflS is located adjacent to aflR, and there is no significant similarity between its putative product and any other proteins found in databases. The gene af $l S$ is clearly involved in aflatoxin regulation since deletion mutants do not produce aflatoxins and the levels of expression of some genes of the aflatoxin pathway are significantly reduced (Yu and Ehrlich 2011; Bhatnagar et al. 2018). Chang (2003) suggested that aflS might be modulating aflatoxin biosynthesis by interacting with aflR although the exact role of aflS has not yet been made clear (Bhatnagar et al. 2018).

\section{Trichothecenes}

Trichothecenes are highly toxic compounds produced by a huge variety of fungal genera (Proctor et al. 2018). However, the characterisation of their biosynthetic pathway has been mainly performed in pathogenic species belonging to the genus Fusarium, most of them included in the Fusarium graminearum Species Complex (FGSC) and causal agents of Fusarium Head Blight disease (Aoki et al. 2014). These mycotoxins are sesquiterpenoids, which are classified as either A or B type depending on the absence or presence of a keto group at the C-8 position of the trichothecene ring (Kimura et al. 2007). Acute intoxication by trichothecene ingestion is related to gastrointestinal disorders, skin irritation, and neuroendocrine changes (Gil-Serna et al. 2014). On the other hand, recent studies showed that immune system is strongly modulated by trichothecene exposure, and surprisingly, these mycotoxins have both immunosuppressive and immunostimulatory effects (Wu et al. 2017).

The main producers of type A trichothecenes are Fusarium sporotrichioides, Fusarium equiseti, Fusarium poae, Fusarium langsethiae, and Fusarium acuminatum, which often contaminate maize, wheat, oat, barley and rye, among others (Gil-Serna et al. 2014). Fusarium graminearum and F. culmorum are considered the most significant producers of type B trichothecenes due to their common occurrence in food products (Kimura et al. 2007). Deoxynivalenol (DON) and nivalenol (NIV) are the most toxic B trichothecenes to both animals and humans and are commonly found in cereals such as maize, oat, barley, and wheat (Gil-Serna et al. 2014).

Trichothecene production has been widely studied, and its complete genetic basis has been reported. The enzymes involved in trichothecene biosynthesis together with their regulatory elements are encoded by 15 genes distributed in three different loci (Merhej et al. 2011). The core TRI cluster presents 10 co-regulated genes including the first cloned one, tri5 encoding trichodiene synthase. All clustered genes are located in the same order and direction in F. sporotrichioides and F. graminearum (Desjardins and Proctor 2007; Moretti et al. 2013). These ten genes encoded 7 structural pathway genes, two regulatory genes, and one transporter (Fig. 2) (Kimura et al. 2007). Furthermore, two additional genomic regions present genes involved in trichothecene biosynthesis in F. sporotrichioides and F. graminearum: the two gene Tril-Tril6 locus and the single gene Tri101 locus (Merhej et al. 2011). Data obtained from several genome studies revealed that these three loci are located in different chromosomes (Moretti et al. 2013). In contrast, an exhaustive analysis of the TRI cluster revealed the presence of Tri1 and Tri101 in the core cluster of some members of the F. incarnatum-F. equiseti group (Proctor et al. 2009), which evidences the complex evolutionary history of trichotheceneproducing Fusarium species.

The expression of the genes involved in trichothecene biosynthesis is coordinated by the regulatory genes, Tri6 and Tri10, located within the core TRI cluster (Merhej et al.

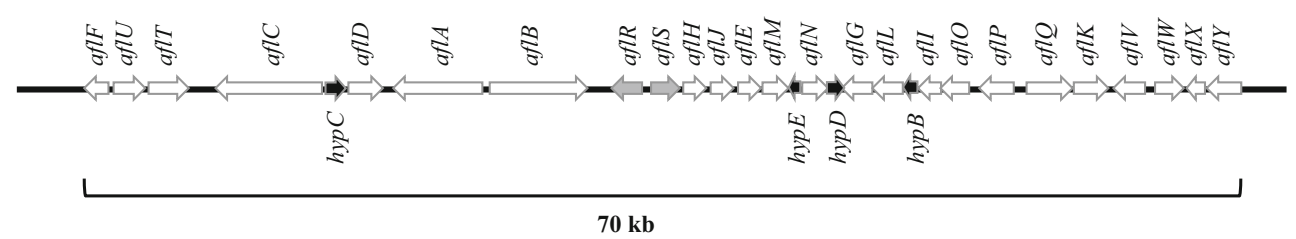

Fig. 1 Scheme of the aflatoxin biosynthetic cluster in Aspergillus flavus. The arrows indicate the direction of the transcription of the genes. Grey arrows correspond to regulatory genes whereas black and white ones are structural genes 


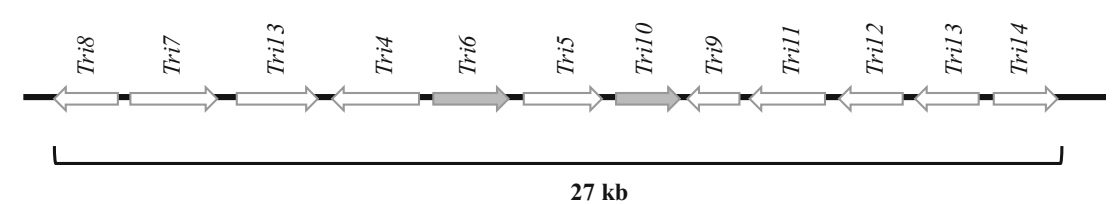

Fig. 2 Scheme of the trichothecene biosynthetic core cluster in Fusarium grami nearum. The arrows indicate the direction of the transcription of the genes. Grey arrows correspond to regulatory genes whereas white ones represent structural genes

2011). Disruption of either of these genes drastically reduces or eliminates the expression of the rest of the TRI genes and therefore suppresses trichothecene production (Alexander et al. 2009). TRI6 protein is a member of the $\mathrm{Cys}_{2} \mathrm{His}_{2}$ zincfinger family and binds to the DNA motif TNAGGCCT that is present in the promoter of every gene of the TRI cluster (Hohn et al. 1999). An alternative binding region (GTGA-(6-50)GTGA) was proposed by Nasmith et al. (2011). Recently, TRI6 has been reported to be not only a pathway-specific, but also a global transcriptional regulator that can modulate the expression of genes associated with nitrogen, carbon, and lipid metabolisms (Nasmith et al. 2011; Lindo et al. 2018). TRI10 structure and its role in trichothecene biosynthesis are not completely known yet. TRI10 protein does not contain any functional domain, and for a long time, it has been considered the master regulator of the expression of Tri6 (Tag et al. 2001). However, Seong et al. (2009) suggests that TRI10 only intensifies the transcriptional effect of TRI6 through TRI6 transcriptional complex assembly.

Some authors considered Tri15 as a fourth single locus involved in trichothecene biosynthesis. The Tril 15 gene encodes a $\mathrm{Cys}_{2} \mathrm{His}_{2}$ zinc-finger and seems to play a negative role in the expression of at least one of the trichothecene genes although its disruption does not affect trichothecene biosynthesis (Alexander et al. 2004).

\section{Fumonisins}

Fumonisins are a group of long-chain amino polyalcohols, of which fumonisin $\mathrm{B}_{1}$ occurs most frequently in cereals and is the most toxic member of the group. It is even associated with oesophageal cancer (Desjardins and Proctor 2007; Gil-Serna et al. 2014). Fumonisins are able to disrupt sphingolipid metabolism leading to sphinganine accumulation in cells and tissues, mainly in the liver and kidney and the nervous system (Stockmann-Juvala and Savolainen 2008).

Fusarium verticillioides is considered the main fumonisin contamination source in maize worldwide although many species of the Fusarium fujikuroi species complex as well as F. oxysporum have been reported as fumonisin producers (Aoki et al. 2014). However, the ability to produce fumonisins is not widespread in the isolates of these species and multiple strains do not even have the biosynthetic genes in their genomes (Moretti et al. 2013). Fumonisins are structurally simple mycotoxins but their biosynthesis requires a complex $42-\mathrm{kb}$ long cluster of genes
(Fig. 3) (Desjardins and Proctor 2007). Up to now, the cluster is supposed to contain 17 co-regulated genes including the first described fum 1, considered the key gene of this pathway, which encodes a polyketide synthase. Its disruption produces the blockage of fumonisin production in Fusarium species (Alexander et al. 2009). Adjacent to fum 1, a transcriptional regulator, fum 21, was described first in $F$. verticillioides and then in other members of Fusarium fujikuroi species complex such as F. proliferatum (Brown et al. 2007; Proctor et al. 2013). The protein, FUM21, presents a Zn(II)2Cys6 DNA-binding domain that suggests its involvement in transcriptional regulation, although, to our knowledge, there are no reports describing the promoter elements recognised to activate transcription of fumonisin biosynthetic genes. However, the involvement of fum 21 in the regulation of fumonisin synthesis is evident, since its deletion mutants have a drastically modified expression of biosynthetic genes such as fum 1 and fum 8 (Brown et al. 2007).

Apart from these species included in the Fusarium fujikuroi species complex, other phylogenetically distant related species have been reported as fumonisin producers. Frisvad et al. (2007) detected fumonisin $\mathrm{B}_{2}$ in cultures of three full genomesequenced strains of $A$. niger associated with the presence of a putative gene cluster for fumonisins. Afterwards, some isolates of $A$. welwitschiae have also been found to be able to produce $\mathrm{FB}_{2}$ (Perrone et al. 2011; Susca et al. 2016). The composition of the fumonisin cluster in Aspergillus section Nigri species is quite different from that reported in Fusarium species and only presents homologues of 11 genes including the transcription factor fum 21 (Fig. 3). Aerts et al. (2018) found that 10 out 12 genes of the fumonisin cluster were downregulated in $\Delta$ fum 21 knockout deletion mutants. The A. niger fumonisin cluster lacks the Fusarium fum 2 gene, which is responsible for the final hydroxylation in the formation of fumonisin $\mathrm{B}_{2}$. Therefore, these Aspergillus species are only able to produce fumonisin $\mathrm{B}_{2}, \mathrm{~B}_{4}$, and $\mathrm{B}_{6}$, but not the most toxic one, fumonisin $\mathrm{B}_{1}$.

The fumonisin cluster in these Aspergillus species was acquired via horizontal gene transfer from a common ancestor, and then, the cluster is diverged by removing and/or reshuffling the genes (Khaldi and Wolfe 2011).

\section{Ochratoxin A}

Ochratoxin A (OTA) is one of the most frequently occurring mycotoxins in human and animal diets and chronic exposure been associated with severe kidney damage (Heusser and 
Fig. 3 Scheme of the fumonisin biosynthetic cluster in Fusarium verticillioides (above) and Aspergillus niger (below). The arrows indicate the direction of the transcription of the genes. Grey arrows correspond to regulatory genes whereas white ones represent structural genes

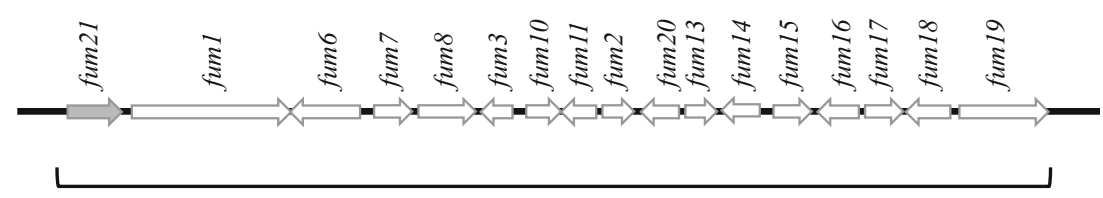

$42 \mathrm{~kb}$

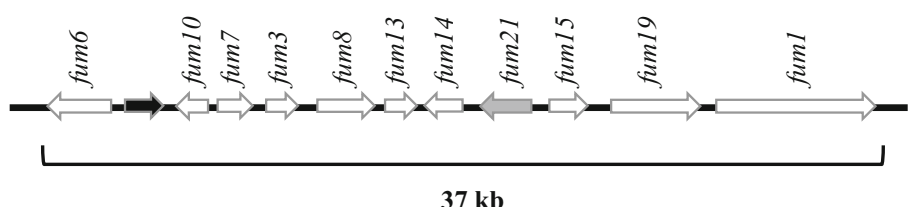

Bingle 2015). Studies focused on human pathologies associated to OTA exposition are still scarce although inhibition of protein synthesis and oxidative stress induction in target cells seem to be the main mechanisms involved (Gil-Serna et al. 2014). OTA contamination of foodstuffs often occurs due to the presence of species included in Aspergillus sections Nigri (A. carbonarius and $A$. niger aggregate species) and Circumdati (A. westerdijkiae and A. steynii) or Penicillium species such as $P$. nordicum and $P$. verrucosum (Malir et al. 2016). OTA is commonly detected in cereals and derivatives, coffee, cacao, grapes and grape-products, spices, nuts and liquorice, among others (Heusser and Bingle 2015).

Among the most important mycotoxins, the genetic basis of ochratoxin A (OTA) biosynthesis is the last one to be described and some important aspects are far from being completely known. OTA consist of a para-chlorophenolic moiety containing a dihydroisocoumarin group linked to Lphenylalanine (Malir et al. 2016). There is controversy regarding how OTA biosynthesis occurs although the most probable pathway was reported by Huff and Hamilton (1979). These authors suggest that OTA synthesis starts from acetate and malonate and presents some intermediate compounds such as ochratoxin $\beta$, ochratoxin $\alpha$, and ochratoxin $C$. These steps would be catalysed by different enzymes including a polyketide synthase (PKS), a non-ribosomal peptide synthetase (NRPS), a cytochrome p450 monooxygenase (P450), and a halogenase or chloroperoxidase that would include the chloride atom to ochratoxin $B$ and, finally, an esterase that would catalyse the last step in the pathway. In recent years, it has been demonstrated that the genes encoding these enzymes are located in a cluster with the only exception being the esteraseencoding one. The cluster of genes involved in OTA biosynthesis are formed by four structural genes encoding a PKS, a
NRPS, a halogenase, and a P450 together with a bZIP transcription factor which is supposed to be the specific regulator of the expression of the structural genes both in Aspergillus and Penicillium species (Fig. 4) (Ferrara et al. 2016; Gil-Serna et al. 2018). Up to now, this same conserved genetic synteny has been reported in A. westerdijkiae, A. steynii, A. niger, A. welwitschiae, A. carbonarius, and in P. nordicum (Susca et al. 2016; Gil-Serna et al. 2018). The palindromic bZIPbinding motifs ATGACGTGTA or TACACGTCAT were found upstream from all the clustered genes, even twice in the case of halogenase, which is the most expressed in permissive conditions for OTA production. This fact suggests the relationship of the clustered bZIP transcription factor in OTA synthesis regulation (Gil-Serna et al. 2018).

Additional PKS encoding genes out of the core cluster have been reported in some species such as A. westerdijkiae, A. carbonarius, $P$. verrucosum, and $P$. nordicum. Their involvement in OTA synthesis has been confirmed by gene disruption, which suppressed toxin synthesis, and they might complement the expression of the clustered PKS-encoding gene under special conditions (Gallo et al. 2017).

\section{General regulator pathways affecting mycotoxin production}

\section{Light and the velvet complex}

Light is a critical factor affecting mycotoxin production by many fungal species that threaten food safety. In general, the ability in vitro of Aspergillus and Penicillium species to produce the toxins is drastically increased under dark conditions

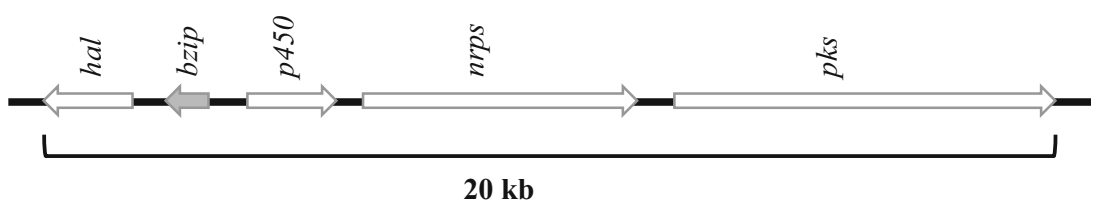

Fig. 4 Scheme of the ochratoxin biosynthetic cluster in Aspergillus carbonarius. The arrows indicate the direction of the transcription of the genes. Grey arrows correspond to regulatory genes whereas white ones represent structural genes 
whereas light has a positive effect on mycotoxin production by Fusarium species (Fanelli et al. 2015).

The effect of light at different wavelengths on OTA production has been reported by several groups. Fungal exposition to white light seems to consistently reduce OTA production in major producers including $P$. nordicum, $P$. verrucosum, A. westerdijkiae, A. carbonarius, and A. niger, although some other wavelengths cause an increased OTA production in A. steynii (yellow and green light) and A. carbonarius (red light) (Schmidt-Heydt et al. 2011; Cheong et al. 2016). The response of Fusarium species to light is different to that observed in OTA-producing species, and in general, light had a positive influence on fumonisin production by $F$. proliferatum and $F$. fujikuroi and trichothecene production by F. graminearum (Schmidt-Heydt et al. 2011; Fanelli et al. 2012a; Matic et al. 2013). In contrast, light has a highly variable effect on fumonisin synthesis by $F$. verticillioides from slight inhibition to a significant increase depending on the strain analysed (Fanelli et al. 2012b; Matic et al. 2013).

The involvement of the velvet complex in that light response has been reported in several cases including aflatoxin production by A. parasiticus and A. flavus (Calvo et al. 2004; Duran et al. 2007), OTA production by A. carbonarius (Crespo-Sempere et al. 2013), fumonisin production by F. verticillioides (Myung et al. 2009; Butchko et al. 2012), and trichothecene production by $F$. graminearum (Merhej et al. 2012). VeA transcription factor is transported to the nucleus where it interacts with LaeA, a master regulator of secondary metabolism in Aspergillus, to control secondary metabolite production. The transport of VeA transcription factor to the nucleus is known to be inhibited by light, and therefore, under light conditions, VeA is mostly located in the cell cytoplasm (Bayram et al. 2008).

Duran et al. (2007) described a blockage of aflatoxin biosynthesis in A. flavus $\Delta v e A$ mutants related to a repression in the expression of the specific transcription factor aflR and the main aflatoxin biosynthetic genes. Similarly, $F$. verticillioides $\Delta v e A$ as well as $\Delta l a e A$ mutants are not able to produce fumonisins and neither the expression of the regulator fum 21 nor structural genes of FUM cluster was detected (Myung et al. 2009; Butchko et al. 2012). Recently, Merhej et al. (2012) reported that $F g V e 1$, the orthologous of veA in $F$. graminearum, also modulate the expression of TRI genes and, therefore, trichothecene production in this species on natural substrates. Crespo-Sempere et al. (2013) found that $\Delta v e A$ and $\triangle l a e A$ knockout-deletion mutants significantly reduced OTA production and it was related to a downregulation of the NRPS encoding gene of the OTA biosynthetic cluster. Moreover, the levels of production of these mutants were similar to those achieved by the wild type under light conditions, which might be due to a relationship between the velvet complex and the reduction of OTA produced by A. carbonarius (Crespo-Sempere et al. 2013).

\section{Oxidative stress}

Fungal response to oxidative stress is based on the production of antioxidant molecules and the activation of enzymes to counteract the oxidants. Additionally, the intracellular presence of reactive oxygen species can also trigger other metabolic responses including triggering mycotoxin synthesis (Reverberi et al. 2010). The modulation of aflatoxin biosynthesis by redox balance has been extensively studied in Aspergillus section Flavi. Jayashree and Subramanyam (2000) suggested that aflatoxin production by A. parasiticus may be a consequence of increased oxidative stress. Subsequently, Reverberi et al. (2006) correlated the expression of aflatoxin biosynthetic genes with the expression of oxidative stress-related transcription factors and an increased activity of antioxidant enzymes. The relationship between oxidative stress and aflatoxin synthesis is supported by the fact that the presence of antioxidant compounds, commonly used in food production such as ethylene or BHA, reduces the expression of biosynthetic genes and, consequently, toxin production (Reverberi et al. 2006; Huang et al. 2009). Reverberi et al. (2012) demonstrated that the presence of oxidative stressors such as t-butyl hydroperoxide or carbon tetrachloride triggered OTA production in A. ochraceus.

This response to oxidative stress by increasing toxin production seems to be related to the participation of transcription factor homologues of the Saccharomyces cerevisiae Yap1 gene. The AP-1 family of transcription factors includes bZIP proteins that activate in response to oxidative stress in yeast and filamentous fungi (Hong et al. 2013). Montiban et al. (2013) described the involvement of Fgapl in the activation of trichothecene production by $F$. graminearum and reported an overexpression of TRI genes by Fgapl-deleted mutants together with an increase in toxin accumulation. Similar results were obtained with the knockout mutants of ApyapA gene in A. parasiticus and Aoyap1 in A. ochraceus, which produce significantly higher levels of aflatoxins and OTA, respectively (Reverberi et al. 2008; Reverberi et al. 2012).

These authors suggested that the disruption of yap 1 homologous genes in mycotoxigenic species affects modulation of toxin biosynthesis because of the fungus' disability to restore the redox balance, which triggers mycotoxin biosynthesis (Reverberi et al. 2008; Reverberi et al. 2012; Montiban et al. 2013).

\section{Osmotic stress}

Osmotic stress is also linked to severe changes in the fungal secondary metabolism, including mycotoxin biosynthesis, and the participation of the high osmolarity glycerol (HOG) pathway has been reported (Duran et al. 2010). Jiang et al. (2011) demonstrated the involvement of response regulator (RR) proteins of the HOG pathway in the regulation of 
trichothecene production in $F$. graminearum. The deletion mutants of some of these regulators showed increased sensitivity to osmotic stress related to a decrease in DON production. The involvement of the HOG pathway in the regulation of fumonisin biosynthesis has been found by Kohut et al. (2009). The deletion of a HOG-type MAP kinase gene, Fphog1, resulted in an increase of fum 1 and fum 8 expression and significant higher levels of fumonisins produced by F. proliferatum in a culture medium.

Osmotic stress has been also reported as an OTA biosynthesis modulator in P. nordicum. This fungus is adapted to high salt-concentrated habitats and high concentrations of $\mathrm{NaCl}$-induced OTA production (Stoll et al. 2013). The authors said that $\mathrm{NaCl}$-induced OTA production in $P$. nordicum is due to a change in the phosphorylation status of the HOG-MAP kinase, which activates transcription factors that might consequently affect OTA biosynthetic genes.

\section{Conclusion}

The regulation of mycotoxin production is a complex process that is still far from being completely clear. Currently, it is already known that regulation not only depends on specific genes of the biosynthetic cluster but also on global regulators that are able to control mycotoxin production due to the modulation of the expression of the genes involved at a transcriptional level. The knowledge of these regulatory routes will allow the development of more effective control methods to avoid the presence of mycotoxins in food products.

Funding information This work was supported by the Spanish Ministry of Science and Innovation (AGL 2014-53928-C2-2-R).

\section{Compliance with ethical standards}

Conflict of interest The author declare that they have no conflict of interest.

\section{References}

Aerts D, Hauer EE, Ohm RA, Arentshort M, Teertstra WR, Phippen C, Ram AFJ, Frisvad JC, Wösten HAB (2018) The FlbA-regulated predicted transcription factor Fum21 of Aspergillus niger is involved in fumonisin production. Antonie Van Leeuwenhoek 111: 311-322. https://doi.org/10.1007/s10482-017-0952-1

Alexander NJ, McCormick SP, Larson TM, Jurgenson JE (2004) Expression of Tril5 in Fusarium sporotrichioides. Curr Genet 45: 157-162. https://doi.org/10.1007/s00294-003-0467-3

Alexander NJ, Proctor RH, McCormick SP (2009) Genes, gene clusters and biosynthesis of trichothecenes and fumonisins in Fusarium. Toxin Rev 28:198-215. https://doi.org/10.1080/ 15569540903092142

Aoki T, O’Donnell K, Geiser DM (2014) Systematics of key phytopathogenic Fusarium species: current status and future challenges. J Gen
Plant Pathol 80:189-201. https://doi.org/10.1007/s10327-0140509-3

Bayram O, Krappmann S, Ni M, Bok JW, Helmstaedt K, Valerius O, Braus-Stromeyer S, Kwon NJ, Keller NP, Yu JH, Braus GH (2008) VelB/VeA/LaeA complex coordinates light signal with fungal development and secondary metabolism. Science 13:1504 1506. https://doi.org/10.1126/science. 1155888

Bhatnagar D, Rajasekaran K, Gilbert M, Cary JW, Magan N (2018) Advances in molecular genomic research to safeguard food and feed supply from aflatoxin contamination. World Mycotoxin J 11:47-72. https://doi.org/10.3920/WMJ2017.2283

Brown DW, Butchko RAE, Busman M, Proctor RH (2007) The Fusarium verticillioides FUM gene cluster encodes a Zn(II)2Cys6 protein that affects FUM gene expression and fumonisin production. Eukaryot Cell 6:1210-1218. https://doi.org/10.1128/EC.00400-06

Butchko RAE, Brown DW, Busman M, Tudzynski B, Wiemann P (2012) Lae1 regulates expression of multiple metabolite gene clusters in Fusarium verticillioides. Fungal Genet Biol 49:602-612. https:// doi.org/10.1016/j.fgb.2012.06.003

Calvo AM, Bok J, Brooks W, Keller NP (2004) veA is required for toxin and sclerotial production in Aspergillus parasiticus. Appl Environ Microbiol 70:4733-4739. https://doi.org/10.1128/AEM.70.8.47334739.2004

Cary JW, Calvo AM (2008) Regulation of Aspergillus mycotoxin biosynthesis. Toxin Rev 27:347-370. https://doi.org/10.1080/ 15569540802373999

Chang PK (2003) The Aspergillus parasiticus protein AFLJ interacts with the aflatoxin pathway-specific regulator AFLR. Mol Genet Genomics 268:711-719. https://doi.org/10.1007/s00438-003-08093

Cheong K, Strub C, Montet D, Durand N, Alter P, Meile JC, Schorr S, Fontana A (2016) Effect of different light wavelengths on the growth and ochratoxin a production in Aspergillus carbonarius and Aspergillus westerdijkiae. Fungal Biol 120:745-751. https:// doi.org/10.1016/j.funbio.2016.02.005

Crespo-Sempere A, Marín S, Sanchis V, Ramos AJ (2013) VeA and LaeA transcriptional factors regulate ochratoxin a biosynthesis in Aspergillus carbonarius. Int J Food Microbiol 166:479-486. https://doi.org/10.1016/j.ijfoodmicro.2013.07.027

Desjardins AE, Proctor RH (2007) Molecular biology of Fusarium mycotoxins. Int J Food Microbiol 119:47-50. https://doi.org/10.1016/j. ijfoodmicro.2007.07.024

Duran RM, Cary JW, Calvo AM (2007) Production of cyclopiazonic acid, aflatrem, and aflatoxin by Aspergillus flavus is regulated by $v e A$, a gene necessary for sclerotial formation. Appl Microbiol Biotechnol 73:1158-1168. https://doi.org/10.1007/s00253-0060581-5

Duran RM, Cary JW, Calvo AM (2010) Role of the osmotic stress regulatory pathway in morphogenesis and secondary metabolism in filamentous fungi. Toxins 2:367-381. https://doi.org/10.3390/ toxins 2040367

Fanelli F, Schmidt-Heydt M, Haidukowski M, Geisen R, Logrieco AF, Mulè $G$ (2012a) Influence of light on growth, fumonisin biosynthesis and FUM1 gene expression by Fusarium proliferatum. Int $\mathrm{J}$ Food Microbiol 153:148-153. https://doi.org/10.1016/j. ijfoodmicro.2011.10.031

Fanelli F, Schmidt-Heydt M, Haidukowski M, Susca A, Geisen R, Logrieco AF, Mulè G (2012b) Influence of light on growth, conidiation and fumonisin production by Fusarium verticillioides. Fungal Biol 116:241-248. https://doi.org/10.1016/j.funbio.2011.11. 007

Fanelli F, Geisen R, Schmidt-Heydt M, Logrieco AF, Mulè G (2015) Light regulation of mycotoxin biosynthesis: new perspectives for food safety. World Mycotoxin J 9:129-146. https://doi.org/10. 3920/WMJ2014.1860 
Ferrara M, Perrone G, Gambacorta L, Epifani F, Solfrizzo M, Gallo A (2016) Identification of a halogenase involved in the biosynthesis of ochratoxin A in Aspergillus carbonarius. Appl Environ Microb 82: 5631-5641. https://doi.org/10.1128/AEM.01209-16

Frisvad JC, Smedsgaard J, Samson RA, Larsen TO, Thrane U (2007) Fumonisin B2 production by Aspergillus niger. J Agr Food Chem 55:9727-9732. https://doi.org/10.1021/jf0718906

Gallo A, Ferrara M, Perrone G (2017) Recent advances on the molecular aspects of ochratoxin A biosynthesis. Curr Opin Food Sci 17:49-56. https://doi.org/10.1016/j.cofs.2017.09.011

Gil-Serna J, Vázquez C, González-Jaén MT, Patiño B (2014) Mycotoxins: toxicology. In: Batt C, Tortorello ML (eds) Encyclopedia of food microbiology, 2nd edn. Elsevier Ltd. Academic Press, Amsterdam, pp 1539-1547. https://doi.org/10. 1016/B978-0-12-384730-0.00234-2

Gil-Serna J, García-Díaz M, González-Jaén MT, Vázquez C, Patiño B (2018) Description of an orthologous cluster of ochratoxin A biosynthetic genes in Aspergillus and Penicillium species. A comparative analysis. Int J Food Microbiol 268:35-43. https://doi.org/10. 1016/j.jffoodmicro.2017.12.028

Heusser AH, Bingle LEH (2015) Comparative ochratoxin toxicity: a review of the available data. Toxins 7:4253-4282. https://doi.org/ 10.3390/toxins 7104253

Hohn TM, Krishna R, Proctor RH (1999) Characterization of a transcription factor activator controlling trichothecene toxin biosynthesis. Fungal Genet Biol 26:224-235. https://doi.org/10.1006/fgbi.1999. 1122

Hong SY, Roze LV, Linz JE (2013) Oxidative stress-related transcription factors in the regulation of secondary metabolism. Toxins 5:683702. https://doi.org/10.3390/toxins5040683

Huang JQ, Jiang HF, Zhou YQ, Lei Y, Wang SY, Liao BS (2009) Ethylene inhibited aflatoxin biosynthesis is due to oxidative stress alleviation and related to glutathione redox state changes in Aspergillus flavus. Int J Food Microbiol 130:17-21. https://doi. org/10.1016/j.ijfoodmicro.2008.12.027

Huff WE, Hamilton PB (1979) Mycotoxins- their biosynthesis in fungi: ochratoxins - metabolites of combined pathways. J Food Protect 42: $815-820$

Jayashree T, Subramanyam C (2000) Oxidative stress as a prerequisite for aflatoxin production by Aspergillus parasiticus. Free Radical Bio Med 29:981-985

Jiang J, Yun Y, Fu J, Shim WB, Ma Z (2011) Involvement of a putative response regulator FgRrg-1 in osmotic stress response, fungicide resistance and virulence in Fusarium graminearum. Mol Plant Pathol 12:425-436. https://doi.org/10.1111/j.1364-3703.2010. 00684.x

Khaldi N, Wolfe KH (2011) Evolutionary origins of the fumonisin secondary metabolite gene cluster in Fusarium verticillioides and Aspergillus niger. Int J Evol Biol 423821:1-7. https://doi.org/10. 4061/2011/423821

Kimura M, Tokai T, Takahashi-Ando N, Ohsato S, Fujimura M (2007) Molecular and genetic studies of Fusarium trichothecene biosynthesis: pathways, genes, and evolution. Biosci Biotechnol Biochem 71: 2105-2123

Kohut G, Adam AL, Fazekas B, Hornok L (2009) N-starvation stress induced FUM gene expression and fumonisin production is mediated via the HOG-type MAPK pathway in Fusarium proliferatum. Int J Food Microbiol 130:65-69. https://doi.org/10.1016/j.ijfoodmicro. 2009.01.002

Kumar P, Mahato DK, Kamle M, Mohanta TK, Kang SG (2017) Aflatoxins: a global concern for food safety, human health and their management. Front Microbiol 7:2170. https://doi.org/10.3389/ fmicb.2016.02170

Lindo L, McCormick SP, Cardoza RE, Brown DW, Kim HS, Alexander NJ, Proctor RH, Gutierrez S (2018) Effect of deletion of a trichothecene toxin regulatory gene on the secondary metabolism transcriptome of the saprophytic fungus Trichoderma arundinaceum. Fungal Genet Biol 119:29-46. https://doi.org/10. 1016/j.fgb.2018.08.002

Lizarraga-Paulín EG, Moreno-Martínez E, Miranda-Castro P (2011) Aflatoxins and their impact on human and animal health: an emerging problem. In: Guevara-González RG (ed) Aflatoxins. Biochemistry and molecular biology. IntechOpen, London, pp 255-282. https://doi.org/10.5772/26196

Malir F, Ostry V, Pfohl-Leszkowicz A, Malir J, Toman J (2016) Ochratoxin A: 50 Years of Research. Toxins 8:191.https://doi.org/ 10.3390/toxins 8070191

Matic S, Spadaro D, Prelle A, Gullino ML, Garibaldi A (2013) Light affects fumonisin production in strains of Fusarium fujikuroi, Fusarium proliferatum, and Fusarium verticillioides isolated from rice. Int J Food Microbiol 166:515-523. https://doi.org/10.1016/j. ijfoodmicro.2013.07.026

Merhej J, Richard-Forget F, Barreau C (2011) Regulation of trichothecene biosynthesis in Fusarium: recent advances and new insights. Appl Microbiol Biotechnol 91:519-528. https://doi.org/10.1007/ s00253-011-3397-x

Merhej J, Urban M, Dufresne M, Hammond-Kosack KE, Richard-Forget F, Barreau C (2012) The velvet gene, FgVe1, affects fungal development and positively regulates trichothecene biosynthesis and pathogenicity in Fusarium graminearum. Mol Plant Pathol 13: 363-374. https://doi.org/10.1111/j.1364-3703.2011.00755.x

Montiban M, Ducos C, Bonnin-Verdal MN, Ponts N, Richard-Forget F, Barreau C (2013) The bZIP transcription factor Fgap1 mediates oxidative stress response and trichothecene biosynthesis but not virulence in Fusarium graminearum. PLoS One 8:e83377. https://doi. org/10.1371/journal.pone.0083377

Moretti A, Susca A, Mulè G, Logrieco AF, Proctor RH (2013) Molecular diversity of mycotoxigenic fungi that threaten food safety. Int J Food Microbiol 167:57-66. https://doi.org/10.1016/j.ijfoodmicro.2013. 06.033

Myung K, Li S, Butchko RAE, Busman M, Proctor RH, Abbas HK, Calvo AM (2009) FvVE1 regulates biosynthesis of fumonisins and fusarins in Fusarium verticillioides. J Agric Food Chem 57:5089 5094. https://doi.org/10.1021/j9900783u

Nasmith CG, Walkowiak S, Wang L, Leung WWY, Gong Y, Johnston A, Harris LJ, Guttman DS, Subramaniam R (2011) Tri6 is a global transcriptional regulator in the phytopathogen Fusarium graminearum. PLoS Pathog 7(9):e1002266. https://doi.org/10. 1371/journal.ppat.1002266

Perrone G, Stea G, Epifani F, Varga J, Frisvad JC, Samson RA (2011) Aspergillus niger contains the cryptic phylogenetic species A. awamori. Fungal Biol 115:1138-1150. https://doi.org/10.1016/j. funbio.2011.07.008

Proctor RH, McCormick SP, Alexnader NJ, Desjardins AE (2009) Evidence that a secondary metabolic biosynthetic gene cluster has grown by gene relocation during evolution of the filamentous fungus Fusarium. Mol Microbiol 74:1128-1142. https://doi.org/10. $1111 / j .1365-2958.2009 .06927 . x$

Proctor RH, Van Hove F, Susca A, Stea G, Busman M, Van der Lee T, Waalwijk C, Moretti A, Ward TJ (2013) Birth, death and horizontal transfer of the fumonisin biosynthetic gene cluster during the evolutionary diversification of Fusarium. Mol Microbiol 90:290-306. https://doi.org/10.1111/mmi.12362

Proctor RH, McCormick SP, Kim HS, Cardoza RE, Stanley AM, Lindo L, Kelly A, Brown DW, Lee T, Vaughan MM, Alexander NJ, Busman M, Gutierrez S (2018) Evolution of structural diversity of trichothecenes, a family of toxins produced by plant pathogenic and entomopathogenic fungi. PLoS Pathog 14:e1006946. https://doi. org/10.1371/journal.ppat.1006946

Reverberi M, Zjalic S, Ricelli A, Fabbri AA, Fanelli C (2006) Oxidant/ antioxidant balance in Aspergillus parasiticus affects aflatoxin 
biosynthesis. Mycotoxin Res 22:39-47. https://doi.org/10.1007/ BF02954556

Reverberi M, Zjalic S, Ricelli A, Punelli F, Camera E, Fabbri C, Picardo M, Fanelli C, Fabbri AA (2008) Modulation of antioxidant defense in Aspergillus parasiticus is involved in aflatoxin biosynthesis: a role for the ApyapA gene. Eukaryot Cell 7(6):988-1000. https:// doi.org/10.1128/EC.00228-07

Reverberi M, Ricelli A, Zjalic S, Fabbri AA, Fanelli C (2010) Natural functions of mycotoxins and control of their biosynthesis in fungi. Appl Environ Microbiol 87:899-911. https://doi.org/10.1007/ s00253-010-2657-5

Reverberi M, Gazzetti K, Punelli F, Scarpari M, Zjalic S, Ricelli A, Fabbri AA, Fanelli C (2012) Aoyapl regulates OTA synthesis by controlling cell redox balance in Aspergillus ochraceus. Appl Microbiol Biotechnol 95:1293-1304. https://doi.org/10.1007/s00253-0123985-4

Rushing BR, Selim MI (2019) Aflatoxin B1: a review on metabolism, toxicity, occurrence in food, occupational exposure, and detoxification methods. Food Chem Toxicol 124:81-100. https://doi.org/10. 1016/j.fct.2018.11.047

Schmidt-Heydt M, Rüfer C, Raupp F, Bruchmann A, Perrone G, Geisen $R$ (2011) Influence of light on food relevant fungi with emphasis on ochratoxin producing species. Int J Food Microbiol 145:229-237. https://doi.org/10.1016/j.ijfoodmicro.2010.12.022

Seong KY, Pasquali M, Zhou X, Song J, Hilburn K, McCormick S, Dong Y, Xu JR, Kistler HC (2009) Global gene regulation by Fusarium transcription factors Tri6 and Tri10 reveals adaptations for toxin biosynthesis. Mol Microbiol 72:354-367. https://doi.org/10.1111/j. 1365-2958.2009.06649.x

Shwab EK, Keller NP (2008) Regulation of secondary metabolite production in filamentous ascomycetes. Mycol Res 112:225-230. https://doi.org/10.1016/j.mycres.2007.08.021

Stockmann-Juvala H, Savolainen K (2008) A review of the toxic effects and mechanisms of action of fumonisin B1. Hum Exp Toxicol 27: 799-809. https://doi.org/10.1177/0960327108099525

Stoll D, Schmidt-Heydt M, Geisen R (2013) Differences in the regulation of ochratoxin a by the HOG pathway in Penicillium and Aspergillus in response to high osmolar environments. Toxins 5:1282-1298. https://doi.org/10.3390/toxins5071282

Susca A, Proctor RH, Morelli M, Haidukowski M, Gallo A, Logrieco AF, Moretti A (2016) Variation in fumonisin and ochratoxin production associated with differences in biosynthetic gene content in Aspergillus niger and A. welwitschiae isolates from multiple crop and geographic origin. Front Microbiol 7:1412. https://doi.org/10. 3389/fmicb.2016.01412

Tag AG, Garifullina GF, Peplow AW, Ake C Jr, Phillips TD, Hohn TM, Beremand MN (2001) A novel regulatory gene, Tri10, controls trichothecene toxin production and gene expression. Appl Environ Microbiol 67:5294-5302. https://doi.org/10.1128/AEM.67.11. 5294-5302.2001

Wang Y, Wang L, Liu F, Wang Q, Selvaraj J, Xing F, Zhao Y, Liu Y, (2016) Ochratoxin A Producing Fungi, Biosynthetic Pathway and Regulatory Mechanisms. Toxins 8 (3):83 https://doi.org/10.3390/ toxins 8030083

Woloshuk CP, Shim WB (2013) Aflatoxins, fumonisins, and trichothecenes: a convergence of knowledge. FEMS Microbiol Rev 37:94 109. https://doi.org/10.1111/1574-6976.12009

Wu Q, Wang X, Nepovimova E, Miron A, Liu Q, Wang Y, Su D, Yang H, Li L, Kuca K (2017) Trichothecenes: immunomodulatory effects, mechanisms, and anti-cancer potential. Arch Toxicol 91:37373785. https://doi.org/10.1007/s00204-017-2118-3

Yu J (2012) Current understanding on aflatoxin biosynthesis and future perspective in reducing aflatoxin contamination. Toxins 4:1024 1057. https://doi.org/10.3390/toxins4111024

Yu J, Ehrlich KC (2011) Aflatoxin biosynthetic pathway and pathway genes. In: Guevara-González RG (ed) Aflatoxins. Biochemistry and Molecular Biology. IntechOpen, London, pp 41-65. https://doi.org/ $10.5772 / 23034$

Yu J, Cary JW, Bhatnagar D, Cleveland TE, Keller NP, Chu FS (1993) Cloning and characterization of a cDNA from Aspergillus parasiticus encoding an O-methyltransferase involved in aflatoxin biosynthesis. Appl Environ Microbiol 59:3564-3571. https:// doi.org/10113/38668

Yu J, Chang PK, Ehrlich KC, Cary JW, Bhatnagar D, Cleveland TE, Payne GA, Linz JE, Woloshuk CP, Bennett JW (2004) Clustered pathway genes in aflatoxin biosynthesis. Appl Environ Microbiol 70:1253-1262. https://doi.org/10.1128/aem.70.3.1253-1262.2004

Publisher's note Springer Nature remains neutral with regard to jurisdictional claims in published maps and institutional affiliations. 